\title{
A Tava Como Elemento Importante na Composição Territorial Mbyá Guarani - Breves Apontamentos
}

\section{Tava as an Important Element in Mbyá Guarani Territorial Composition: Brief Notes}

\author{
Helena Amanda Faller Tagarro \\ Instituto do Patrimônio Histórico e Artístico Nacional \\ Brasília, DF, Brasil
}

\begin{abstract}
Resumo: Antes, eram donos de toda essa terra; hoje, os povos indígenas precisam lutar para terem suas identidades e direitos reconhecidos; seu território se tornou restrito e imputado pelo Estado, muitas vezes sem levar em consideração a trajetória histórica e cultural e as relações territoriais existentes. O objeto de análise deste trabalho se refere à Região das Missões localizada no Rio Grande do Sul, local onde os missionários espanhóis fundaram seus povoados. A proposta é introduzir o debate acerca da relação dos Mbyá Guarani com o território, apresentando suas características e deslocamentos, o território político e cultural, além de problematizar a participação indígena nos processos de reconhecimento do Patrimônio Cultural Brasileiro na região missioneira.
\end{abstract}

Palavras-chave: Território; Identidade; Indígena.

Abstract: Once the owners of all of the land, today indigenous peoples must struggle to have their identities and rights recognized and over time their territory has been restricted and imputed by the State, often without taking into account their historical and cultural trajectory and their existing territorial relations. This study explores the relationship of the Mbyá Guarani with their territory in the Region of the Missions (Rio Grande do Sul state). In the past Spanish clerics founded mission villages for the Mbyá Guarani. These villages are characterized, population displacements traced and the political and cultural territory described. Finally, the role of indigenous participation in the process of recognition of a Cultural Heritage Site in the Missions region is evaluated.

Keywords: Territory; Identity; Indigenous

\section{Introdução}

A região das Missões, no Rio Grande do Sul, guarda uma historicidade complexa que envolve a participação dos jesuítas, dos indígenas e das duas Coroas Ibéricas. Território inicialmente pertencente aos nativos da América, foi invadido por colonos e

Geógrafa pela UFES; Mestranda em Preservação do Patrimônio Cultural pelo IPHAN. helenafaller.89@gmail.com. https://orcid.org/0000-0002-6753-3325 
missionários espanhóis, durante os séculos XVI e XVII, que se apossaram atribuindo a ele uma nova forma de organização social e espacial. Embora, atualmente, este território pertença ao Brasil, a presença espanhola no período colonial se justifica pela assinatura do Tratado de Tordesilhas, em 1494. O tratado estipulou uma linha divisória do continente americano, designando o território oriental à Portugal e o ocidental à Espanha (MAEDER, 2009). Portanto, o que hoje se refere ao estado do Rio Grande do Sul, no período colonial pertencia à Coroa Hispânica.

O território em questão foi ocupado por missionários da Companhia de Jesus que fundaram povoados com características comunitárias, com áreas de cultivos de pastagem, além de uma infraestrutura urbana (STELLO, 2013). A fundação desses povoados teve como proposta a evangelização dos povos indígenas que habitavam aquela região, fazendo com que eles fossem "reduzidos" aos padrões culturais europeus, o que explica o termo redução também associado aos povoamentos (BAPTISTA, 2010). Entretanto, para além deste propósito, havia o interesse da consolidação do poder político e social por parte dos europeus sobre sua colônia. As ações, de certo modo, deram certo, apesar das diversas dificuldades que surgiram durante o processo, mas acabaram recebendo grande prestígio diante da coroa espanhola ainda no período colonial (MAEDER, 2009).

Para o pleno funcionamento desejado pelos jesuítas, as reduções eram constituídas por áreas que atendiam tanto os padres quanto os indígenas, além das áreas comunitárias que eram utilizadas por todos. Apesar de possuir uma infraestrutura aparentemente democrática, as reduções tinham um caráter bastante hierárquico, sendo os religiosos os maiores representantes do poder (BAPTISTA, 2010).

Em contrapartida, para que houvesse uma boa convivência entre os nativos e os jesuítas, foi necessário atribuir ao primeiro grupo poder de autonomia dentro dos povoados, pois, ainda que os jesuítas detivessem a maior centralidade do poder, ainda que estivessem no nível mais alto da hierarquia, muitos indígenas permaneciam resistentes às suas ordens, mantendo-se fiéis apenas aos seus caciques. E para que todos os nativos que optaram por viver dentro dos povoados produzissem conforme os anseios dos religiosos, era importante ceder parte do poder. Assim, segundo Baptista (2010), na composição espacial das reduções, havia uma área conhecida como cacicados, que podem ser entendidos como espaços reservados para uso familiar, muito comum aos modelos de organização dos próprios Guarani.

Há alguns autores que buscam apresentar a aliança formada entre os indígenas e os jesuítas como algo positivo ao primeiro grupo, ao considerarem que estando dentro das reduções eles estariam protegidos dos colonos, como aponta Baptista (2010, p. 18), onde "os povoados missionais são representados como locais seguros e confortáveis aos indígenas graças a um conjunto de benesses urbanísticos e tecnológicos apresentados pelos padres". Por outro lado, há outros autores, como Pontes, que discordam e trazem outra perspectiva, segundo a qual "nas reduções os indígenas estavam mais protegidos da escravidão pelos colonos, no entanto, estavam submissos ao trabalho servil imposto pelos jesuítas" (2010, p. 58).

E foi com o uso desse trabalho servil que muitos povoados conseguiram prosperar. A mão de obra indígena se tornou base da produção interna das reduções, apesar de 
não gerar excedentes, uma vez que não faz parte da tradição Guarani produzir além do necessário, o que, de certa forma, desagradava os religiosos (BAPTISTA, 2010). Porém, vale dizer que foram os indígenas os maiores responsáveis pela construção de inúmeras igrejas ao longo do território jesuítico. Graças a sua força de trabalho e seu empenho os povoados se desenvolveram, chegando ao número de trinta povos espalhados entre Argentina, Brasil e Paraguai, dando origem à Província Jesuítica do Paraguai (STELLO, 2013). No território que hoje pertence ao Estado brasileiro, encontram-se os remanescentes de sete desses trinta povos.

Os povoamentos de Santo Ângelo Custódio, São Francisco Borja e São Luiz Gonzaga tiveram seus resquícios sobrepostos pelas cidades que surgiram ao longo do tempo. Os outros quatro sítios mantiveram alguns vestígios das antigas reduções e foram todos tombados pelo Instituto do Patrimônio Histórico e Artístico Nacional (Figura 1), sendo eles São Miguel Arcanjo, São João Batista, São Nicolau e São Lourenço Mártir. Os sítios de São João Batista, São Nicolau e São Lourenço Mártir foram inscritos no Livro Histórico em 1970. Já o de São Miguel Arcanjo foi inscrito no Livro de Belas Artes em 1938, e declarado Patrimônio Mundial pela UNESCO, em 1983. Ademais, todos os quatro sítios históricos foram reconhecidos como Patrimônio Cultural do MERCOSUL, em 2015, em conjunto com Argentina, Bolívia, Paraguai e Uruguai, com o título de Missões Jesuíticas Guarani, Moxos e Chiquitos ${ }^{1}$.

Quatro sítios históricos identificados, valorados e acautelados via legislação federal de tombamento, sem contar os reconhecimentos que ultrapassam os limites nacionais; mas eis um questionamento que muito me intriga: em meio a essas narrativas, houve a participação dos indígenas? Trago esta questão tendo em vista que é inevitável reconhecer o papel fundamental que os mesmos tiveram na construção desses bens que hoje chamamos de patrimônio. Desta forma, se eles fizeram parte do processo histórico de formação e consolidação das reduções, por que não trazê-los como os protagonistas que também são dessa mesma história? Não pretendo aqui afirmar que as narrativas indígenas foram excluídas ou negligenciadas, mas sim problematizar essa situação.

Ademais, em 2014 ocorreu o registro da Tava, inscrita no Livro de Lugares como Tava, Lugar de Referência para o Povo Guarani. Esse registro, fruto do Inventário Nacional de Referências Culturais (INRC) dos Mbyá Guarani do Rio Grande do Sul, trouxe em perspectiva um novo olhar sobre o território missioneiro. Tanto a realização do inventário, quanto o registro da Tava, contribuíram para ampliar o debate acerca da territorialidade Guarani, que, como busco apresentar neste trabalho, demonstram haver uma forte relação cosmológica, considerando que todos os espaços ocupados por esse povo são inicialmente definidas pelos karaí (líderes espirituais) através da identificação das Tava, ou seja, ocorre uma identificação da sacralidade do lugar e, em seguida, a sua ocupação. 


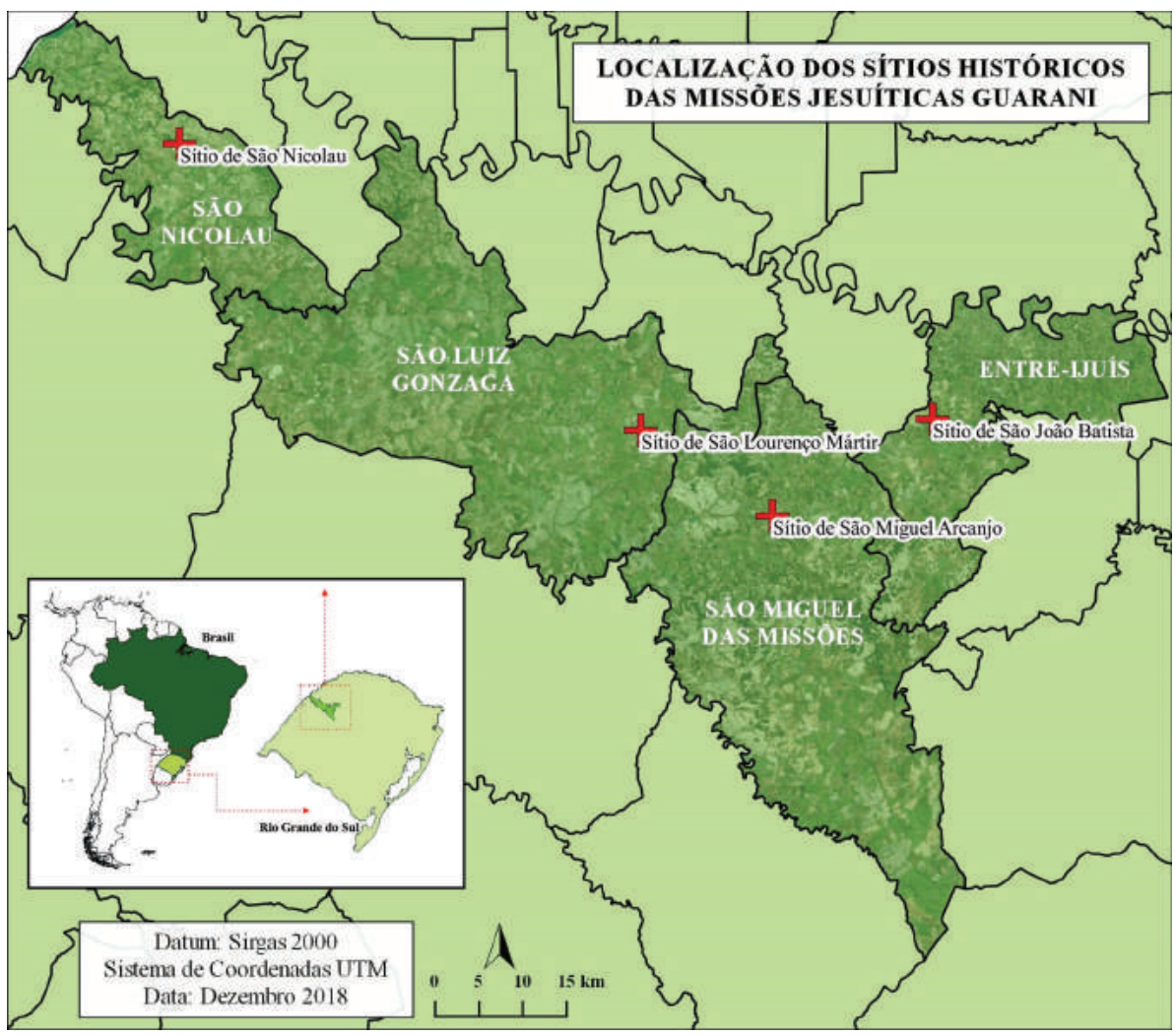

Figura 1: Mapa de localização dos quatro sítios históricos acautelados pelo IPHAN Fonte: Geoserver IPHAN/ IBGE.

É perceptível que a existência das Tava está intrinsecamente relacionada com a territorialidade Mbyá Guarani, e a patrimonialização da Tava de São Miguel Arcanjo é uma maneira de reconhecer e valorizar a cultura Mbyá, bem como a participação desse povo nos processos históricos do Brasil. Em verdade, os Mbyá Guarani não só contribuíram na formação histórica brasileira através das instalações das reduções jesuíticas no sul do país, como também em outros países sul-americanos, como Argentina e Paraguai. Assim, em outubro de 2018, ocorreu o seu mais recente reconhecimento como Patrimônio Cultural do MERCOSUL, criando um novo espaço de debate acerca de sua territorialidade que ultrapassa os limites nacionais. E pensando na relação Tava x território Mbyá, há uma explanação acerca desse novo reconhecimento e a importância dele para aquele povo.

Vale ressaltar que, no âmbito do MERCOSUL, existem dois reconhecimentos distintos do patrimônio cultural. O primeiro, ocorrido em 2015, se refere aos quatro sítios históricos reconhecidos junto com outros sítios localizados na Argentina, Bolívia, Para- 
guai e Uruguai; trata-se de um bem de natureza material e caráter transnacional. A Tava é outro bem reconhecido pelo bloco, em 2018, porém de natureza imaterial e, apesar de estar associado ao território tradicional Guarani que ultrapassa os limites nacionais, não se trata de patrimônio transfronteiriço.

O presente trabalho tem como proposta trazer para o debate a relação que o povo Mbyá Guarani tem com o seu território, considerando as existências das Tava que ajudam no processo de ocupação e formação territorial. Assim, o trabalho busca apresentar o território sob duas perspectivas: a política, em que o território é delimitado política e juridicamente; e a cultural, que remete ao território tradicional Guarani, existente a partir dos movimentos de deslocamento e de ocupações ao longo do tempo, é um território que não obedece aos limites políticos. Ademais, há também uma breve explanação sobre o que é uma Tava e como se deu o reconhecimento da Tava presente no Sítio Histórico de São Miguel Arcanjo, localizado no município de São Miguel das Missões/RS, como Patrimônio Imaterial Brasileiro, pelo Instituto do Patrimônio Histórico e Artístico Nacional - IPHAN, e como Patrimônio Cultural do MERCOSUL.

Embora a proposta deste estudo seja de discutir a relação das Tava, em especial a Tava de São Miguel Arcanjo, com o território Guarani, não é intento aqui aprofundar tal discussão. Trata-se, portanto, de um estudo que traz breves apontamentos iniciais a respeito da temática. Para tanto, a metodologia utilizada é de pesquisa bibliográfica, em que foram selecionadas algumas bibliografias como livros, artigos, dissertações de mestrado e teses de doutorados que apresentam ligações com o tema, para contribuir nessa construção. Havia-se, inicialmente, a proposta de se realizar uma visita de campo na Aldeia Alvorecer (Tekoá Koenju), em São Miguel das Missões/RS, para conhecer empiricamente essa relação do povo com o território, assim como para coletar informações importantes para o desenvolvimento do trabalho. Contudo, tal visita não pôde ser realizada, o que culminou na impossibilidade de aprofundamento do tema e, por esta razão, são trazidos aqui alguns breves apontamentos com bases bibliográficas que se dividem em apresentação sobre o território Mbyá Guarani e a Tava enquanto Patrimônio Cultural.

\section{O Território Mbyá Guarani}

O povo Guarani mantém uma relação íntima com a natureza, de modo que eles só ocupam ambientes propícios à sua sobrevivência, pois, para eles, deve-se usufruir apenas o necessário, o que lhes cabe. Há uma dificuldade de se estabelecerem em um espaço por conta doseu modo de vida, que se baseia na subsistência. Assim, em áreas pouco extensas, onde a concentração de elementos naturais para a subsistência do grupo é pouco favorável, ocorre um fluxo migratório mais intenso para outros locais, dando ao antigo o direito de regeneração (TEAO, 2015). Essa relação de uso do território, extraindo somente o que é preciso, é reflexo do modo de vida Guarani, que transcende as questões ambientais pertencentes ao pensamento ocidental; na verdade, está muito ligado às questões místicas e cosmológicas do grupo, que acredita que extrapolar os limites da natureza, isto é, danificar o ambiente causará "a fúria de seus 'donos'" (IPHAN, 2014, p. 8). 
No entanto, "os donos" a que se referem são os "seres encantados" que guardam e protegem a terra, os primeiros Mbyá; isso porque, para esse grupo, a terra não possui dono, tendo todos o igual direito de ocupar e usufruir dela (LADEIRA, 1997). Apesar da crença de que a terra não pertence a ninguém, os Mbyá Guarani acreditam na existência de um território tradicional deles, um território que foi habitado por seus ancestrais que atingiram a imortalidade, alcançando a "Terra sem Mal". Esse território tradicional Guarani se expressa através de um itinerário percorrido pelos Mbyá do passado, que foram deixando marcas ao longo do tempo, e que hoje está presente no ideário de seus descendentes, o que reflete na dimensão cultural do território explicada por Haesbaert (2011).

O território tradicional Guarani é compreendido por áreas existentes na parte oriental do Paraguai, no nordeste da Argentina e no leste brasileiro, que se estende desde o Rio Grande do Sul até o Espírito Santo (IPHAN, 2014; TEAO, 2015). O mapa a seguir (Figura 2) mostra a mancha do que seria a representação atual do território tradicional Guarani, construído com base no Mapa Digital Guarani², em que são apontados os locais onde ainda há ocorrência da presença Guarani na América do Sul. Em toda essa mancha espacial eles estão presentes, pois é nela que realizam suas peregrinações em busca da morada celeste, além de se tornar uma representação da "territorialidade livre", que se refere a um dos princípios estabelecidos por eles e que se encontra no Dossiê de Registro da Tava, documento elaborado em 2014 pelo IPHAN como base para o registro da Tava de São Miguel Arcanjo como referência cultural Guarani. Essa "territorialidade livre" consiste no reconhecimento do direito dos Guarani de transitarem livremente pelo seu território tradicional (IPHAN, 2014).

Além da "territorialidade livre", há mais dois princípios apresentados pelos Guarani, sendo eles a "natureza livre" e "respeito à dimensão do segredo" (IPHAN, 2014, p. 8). A "natureza livre" está relacionada ao que já foi abordado anteriormente, ao respeito dado à natureza, a sobrevivência ocorrida através da moderação. A preservação, para eles, ultrapassa o sentido de proteger para manter, sendo mais uma questão de ser e de pertencer ao ambiente. O princípio de "respeito à dimensão do segredo" pode ser entendido como o direito de escolha do grupo do que deve ou não ser transmitido ao restante da sociedade, é a compreensão "de que há aspectos da cultura dos Guarani-Mbyá que só a eles pertencem e que não devem ser publicizados. (...) cabe a eles definir o que deve ser divulgado e o que deve permanecer como segredo com relação aos seus saberes" (IPHAN, 2014, p. 8). 


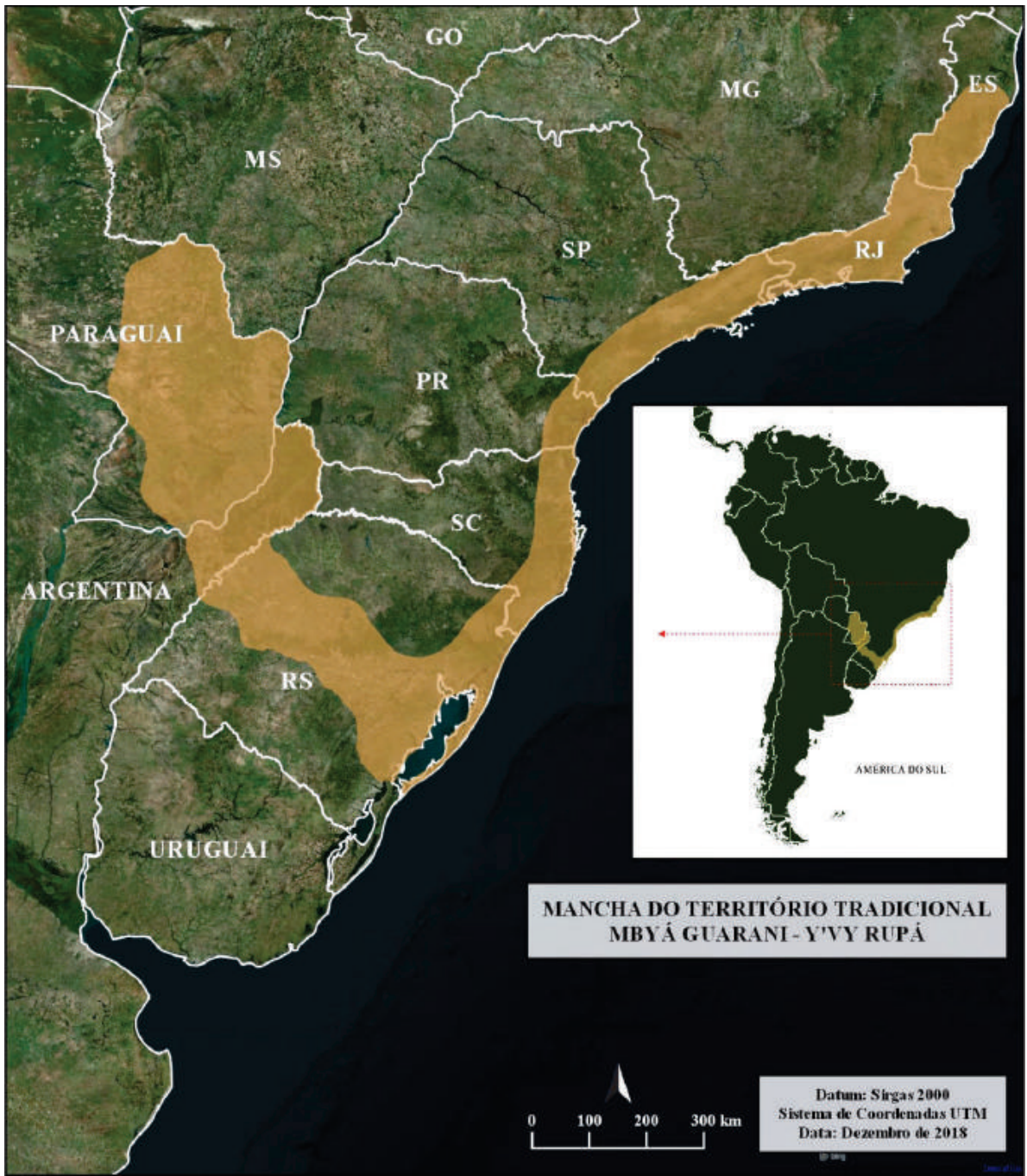

Figura 2: Distribuição do Território Tradicional Mbyá Guarani - Y'vy Rupá Fonte: Geoserver IPHAN/ IBGE/ Cartografia Cultural Guarani IPHAN.

O entendimento acerca desses três princípios apresentados surgiu a partir do desenvolvimento do Inventário Nacional de Referências Culturais (INRC), realizado pelo IPHAN, entre os anos de 2004 a 2008, nas seguintes aldeias: Tekoá Koenju, Tekoá Porã, Tekoá Yryapu e Tekoá Anhetenguá (Figura 3). Ademais, também o inventário possibilitou no conhecimento da existência da Tava no sítio de São Miguel Arcanjo, um dos quatro acautelados pela legislação federal de tombamento, além de ser reconhecido como Patrimônio Mundial e do MERCOSUL. 


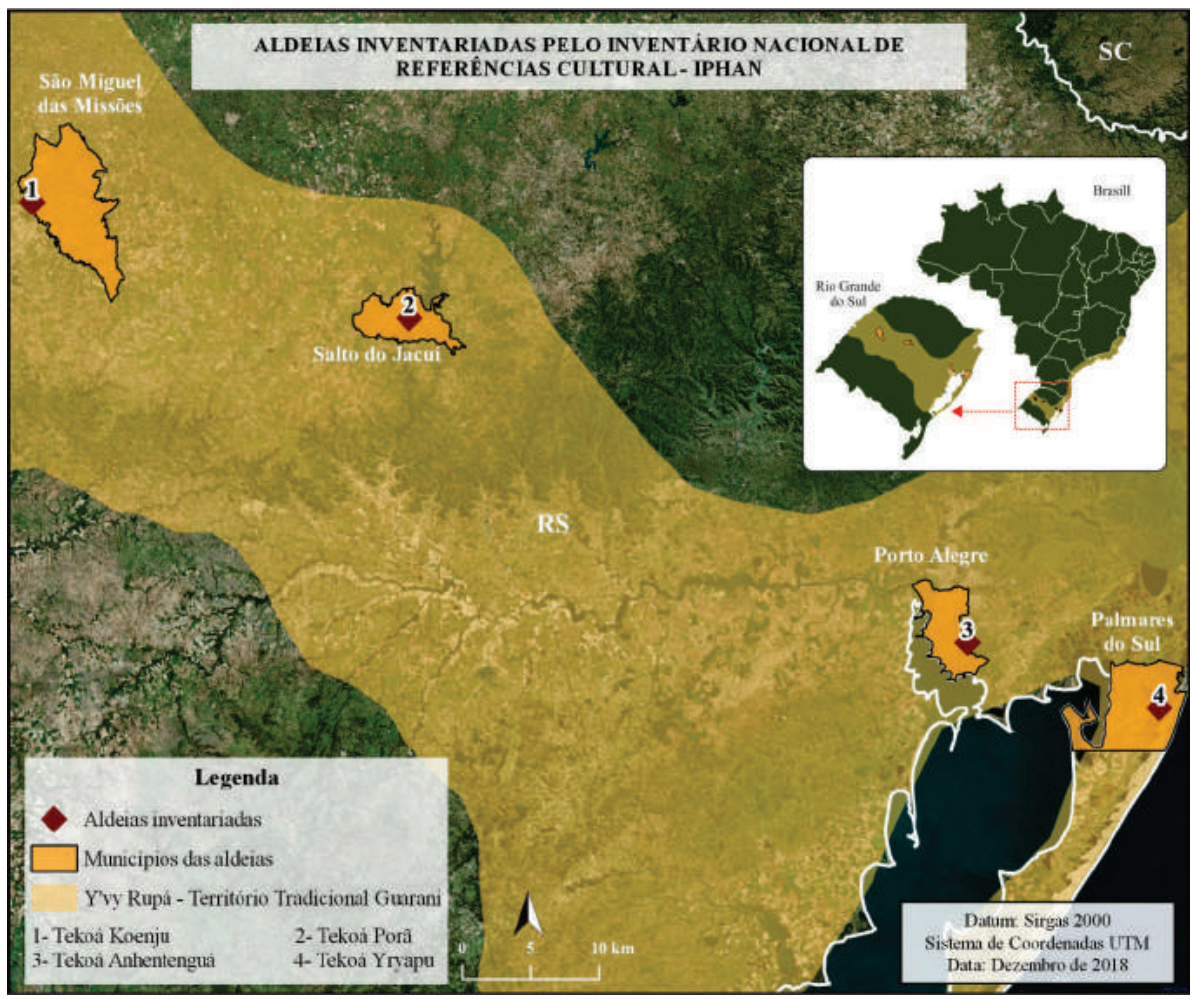

Figura 3: Localização das aldeias inventariadas pelo INRC dos Mbyá Guarani no Rio Grande do Sul.

Fonte: Geoserver IPHAN; IBGE; Cartografia Cultural Guarani IPHAN.

Para os Guarani, a Tava representa "um local sagrado onde viveram seus antepassados" (IPHAN, 2014, p. 29) e é tão significativa que só pode ser vista pelos karaí, líder espiritual Mbyá, e geralmente é associada a elementos da natureza, como formação rochosa e relevo. Por outro lado, a Tava localizada em São Miguel das Missões possui uma particularidade por ser visível tanto aos olhos dos outros Mbyá, quanto aos olhos dos Juruá (não indígenas), e também por se tratar de uma construção e não um elemento natural (Figura 4). E essa particularidade é explicada pelos Guarani como sendo o desejo de Nhanderu fazer dela visível para que todos possam acreditar nas narrativas sagradas e, assim, viver de maneira consciente e respeitosa tanto entre si quanto com a natureza (IPHAN, 2014). 


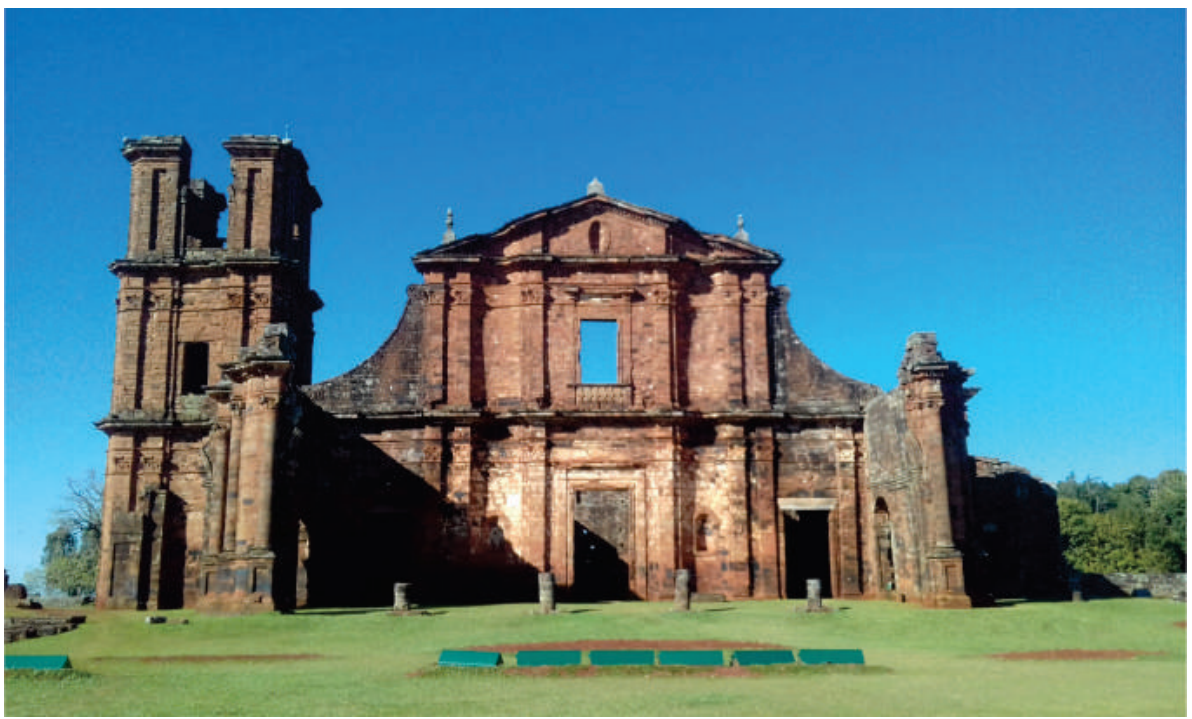

Figura 4: Remanescentes da Igreja de São Miguel Arcanjo e Tava para o povo Mbyá Guarani - São Miguel das Missões/RS.

Foto: Helena Faller (Agosto/2018).

A Tava, como um lugar simbólico, torna-se também um lugar referencial para a territorialidade Mbyá, pois é a partir de sua identificação que o grupo começa a constituir o seu território, erguendo inicialmente uma opy (casa de oração) nas proximidades e, em seguida, edificando uma nova aldeia para dar continuidade ao modo de vida Guarani. De acordo com o dossiê de registro (IPHAN, 2014), quem determina o local para o estabelecimento das tekoá (aldeias) são os karaí, pois são os únicos capazes de enxergar os sinais deixados por seus ancestrais, sendo um desses sinais a própria Tava, como já foi mencionado anteriormente. Tava significa "casa de pedra", e segundo o IPHAN, "são lugares que já tiveram a presença de imortais, isto é, dos primeiros Mbyá, que se encantaram e hoje moram na Terra sem Mal" (2014, p. 27).

Diante do que tem sido exposto neste trabalho, fica perceptível que a composição territorial dos Mbyá Guarani muito está relacionada com sua cosmologia, mantendo uma relação de respeito com a natureza e, ao mesmo tempo, obedecendo determinações de seus ancestrais - expressadas através dos karaí - de onde devem ocupar e se estabelecer. Além disso, fica perceptível a não permanência deles no mesmo espaço por muito tempo, uma vez que estão sempre em movimento. E esses deslocamentos ocorrem, pode-se dizer, por duas razões distintas. A primeira é alusiva às questões místicas, quando saem em busca de sua imortalidade, em busca da Terra sem Mal, retornando à ideia de "territorialidade livre" como um dos princípios Guarani. A outra razão é decorrente dos conflitos fundiários que os força, muitas vezes, a buscar outros espaços, como 
aponta Teao (2015) e Ladeira (1996), sendo uma realidade que atinge não apenas os grupos Mbyá, mas diversas outras etnias no Brasil.

Os deslocamentos Mbyá são uma constante e ocorrem desde antes da chegada dos luso-hispânicos a terras ameríndias. Porém, por viverem em movimento, acabam sendo impedidos do direito à terra, havendo dificuldades nos processos de demarcação e reconhecimento. Uma das saídas encontradas por eles, como explica Teao (2015), é de firmar acordos com outros grupos indígenas que possuem terras regularizadas, como o que ocorre no Espírito Santo. Por outro lado, Ladeira (1996) vem dizer que para os Mbyá, torna-se imprópria a redução de território ao que entendemos por terras indígenas, pois para eles, o conceito de território supera os limites físicos das aldeias e trilhas e está associado a uma noção de mundo que envolve a redefinição constante das relações multiétnicas, o compartilhar e dividir espaços (LADEIRA, 1996, p. 785).

Desta forma, é possível compreender o território Mbyá como processo, relação de fluidez; e não como um elemento fixo e delimitado no espaço. O território tradicional Guarani pode ser definido como processo de territorialização Mbyá, que culturalmente permanecem em movimento, mantendo as relações sociais e de reciprocidade entre as aldeias (LADEIRA, 1997).

\section{A Tava Guarani enquanto Patrimônio Cultural}

O processo de reconhecimento da Tava como Patrimônio Cultural Brasileiro teve início com a realização do Inventário Nacional de Referências Culturais dos Mbyá Guarani situados no estado do Rio Grande do Sul. O inventário teve início no ano de 2003, fruto da proposta de mudar a exposição do Museu das Missões, localizado no Sítio de São Miguel Arcanjo que há muito tempo não havia sido modificada, o que acarretou numa estagnação das narrativas históricas apresentadas pelo próprio museu. Outro elemento que se apresenta com o mesmo discurso histórico por décadas é o espetáculo "Som e Luz" que ocorre desde a década de 1970 e se mantém igual desde então, sofrendo alguns ajustes técnicos apenas. É fato que quando falamos sobre narrativas, nos referimos à forma como interpretamos a sociedade e sua história, trata-se da acepção que temos sobre a realidade, é uma referência da nossa própria identidade. E entendendo a identidade como a relação de experiências vividas cotidianamente, ela permanece em constante transformação (HALL, 2011), assim como o nosso entendimento sobre o mundo. Portanto, a nossa identidade influencia na forma como narramos o mundo, logo, as narrativas tendem a não permanecer as mesmas.

O que se pretende dizer é que, em São Miguel das Missões, tanto na exposição do Museu das Missões quanto no espetáculo "Som e Luz", as narrativas ali contidas não seguiram as transformações adotadas por pesquisadores da história, antropologia e outras disciplinas em âmbito nacional. Havia uma falta de coerência entre o que se falava sobre a história da região e o que se encontrava ali representado. Antes da realização do INRC, as narrativas ainda traziam o jesuíta como herói civilizador, deixando os Guarani em segundo plano, como grupos frágeis que precisavam ser protegidos, não reconhecendo sua importância em todo esse processo de formação reducional. E naquele período, no início dos anos 2000, o Instituto do Patrimônio Histórico e Artístico Nacional começava 
a implementar ações vinculadas às novas políticas de referências culturais, como o Decreto 3.551/2000 que reconhece um bem como Patrimônio Imaterial Brasileiro. Deste modo, as referências culturais das minorias também passaram a ser valorizadas e estudadas, como ocorreu como os Mbyá Guarani do Rio Grande do Sul, mais especificamente da Região das Missões.

Somando a estagnação das narrativas presentes no Sítio Histórico de São Miguel Arcanjo com as novas políticas de referências culturais, pensou-se em realizar um INRC naquela região. Porém, a razão que levou à realização do INRC no Rio Grande do Sul foi a ocupação diária dos Mbyá Guarani naquele sítio para comercializar seus artesanatos. A ocupação deles ali era curiosa, pois se fosse somente para vender suas produções, eles poderiam fazer em qualquer outro local, inclusive em áreas com maior número de pessoas transitando. Havia ali algum motivo especial, e a proposta do INRC era de descobrir qual. As perguntas que nortearam a realização desses trabalhos foram: Qual o sentido da presença deles neste sítio? E teria alguma representatividade?

Ao longo do desenvolvimento do inventário foi identificada a existência da Tava nos remanescentes da Igreja de São Miguel Arcanjo, além de começar a compreender a sua importância para povo Guarani. Essa identificação resultou em seu registro como Patrimônio Imaterial Brasileiro em 2014, no Livro dos Lugares com o título de Tava: Lugar de Referência para o Povo Guarani. Esse reconhecimento trouxe em perspectiva outro olhar sobre o patrimônio; o território que outrora era evidenciado pela presença jesuítica ganhou novos limites, agora com a Tava não se trata mais apenas das reduções - não que essa parte da história não seja importante ou não mereça ser reconhecida - mas também da historicidade e das referências culturais indígenas, o papel que o povo Guarani teve na construção histórica do país. Há uma nova abordagem sobre aquele espaço, que se integra aos contextos históricos de outros países sul-americanos, como Argentina e Paraguai, que também passaram pelo projeto missional através da implementação das reduções jesuíticas, inclusive, com o uso de mão de obra indígena.

Essa presença das reduções jesuíticas Guarani em outros países além do Brasil possibilita o reconhecimento da Tava como Patrimônio Cultural do MERCOSUL, sendo que, para ocorrer tal reconhecimento, é necessário que haja integração do bem entre dois ou mais países que compõem o bloco. Isso acontece pois a integração é o fator preponderante para o desenvolvimento de qualquer área dentro do MERCOSUL, uma vez que ela é componente base da assinatura do Tratado de Assunção, responsável por criar e instituir o MERCOSUL, em 1991. Portanto, é fundamental que o patrimônio a ser reconhecido pelo MERCOSUL expresse, de alguma maneira, o processo integracionista proposto pelo bloco, seja por questões históricas ou artísticas, refletindo o passado ou o presente; o que importa é que o bem possa ser representativo para a região e não apenas para um país.

Uma das razões que leva a compreender a Tava como elemento de integração do MERCOSUL Cultural é a existência do território tradicional Guarani, o Y’vy Rupá, que se forma e se transforma à medida em que os Mbyá caminham em busca de sua Terra sem Mal. Ele existe além dos limites geopolíticos estabelecidos, está presente na subjetividade Guarani, e para se manter vivo necessita das relações sociais entre os grupos, ou seja, é necessário manter em voga o princípio da territorialidade livre, 
que consiste no caminhar livremente pelo território tradicional, visitando parentes, identificando novas Tava, erguendo novas aldeias; e considerando que este território tradicional ocupa parte do Paraguai, da Argentina e do Brasil, o reconhecimento da Tava como Patrimônio Cultural do MERCOSUL a transforma no alicerce do debate acerca do percurso dos Guarani por entre os três países. A Tava é a representação não só da integração política entre esses Estados, como também é o reflexo da integração cultural entre diferentes povos e culturas.

O reconhecimento da Tava de São Miguel Arcanjo não dá aos Guarani o poder de atravessar as fronteiras políticas dos Estados sempre que quiserem, mas possibilita uma sensibilização aos países envolvidos de discutirem uma política pública específica para essa situação. Além disso, esse reconhecimento não é relevante apenas para o povo Guarani, visto que para esse povo, todo remanescente de redução, é identificado por eles como Tava, por se tratar de construções de pedra realizadas por seus antepassados mediante permissão de Nhanderu (IPHAN, 2014). Portanto, a existência dessas Tava intensifica a participação desse grupo no desenvolvimento do projeto missional, sem contar que essas edificações são marcas do passado missioneiro, parte da formação histórica sul-americana, pois foi aqui que tal projeto se consolidou, formando os trinta povos das missões que juntos constituíram a antiga Província Jesuítica do Paraguai (STELLO, 2013). Com a atual delimitação político-territorial da América Latina, esses trinta povos encontram-se distribuídos entre quinze na Argentina, oito no Paraguai e sete no Brasil; porém, apenas vinte apresentam algum vestígio do passado reducional, dos quais quatro estão localizados em território brasileiro (Figura 5).

A respeito desses vinte sítios históricos que estão distribuídos nos três países da América do Sul, vale chamar a atenção para que sete deles foram identificados e reconhecidos como Patrimônio Mundial pela UNESCO. O remanescente localizado no Brasil e que se tornou Patrimônio Mundial é o Sítio Histórico de São Miguel Arcanjo, ou seja, local onde se encontra Tava, recém reconhecida pelo MERCOSUL. Tal sítio, em âmbito da UNESCO, foi reconhecido em conjunto com mais quatro situados na Argentina, formando um bem seriado e transfronteiriço.

Assim, fica perceptível que seja pela cosmologia Guarani, seja pela história missioneira, não há como negar a importância da Tava para o MERCOSUL e sua capacidade de promover a integração que o bloco tanto busca. Ademais, a presença de outros sítios históricos ajuda a fortalecer a integração por meio de uma nova composição territorial, um espaço além das fronteiras, delimitado a partir de relações culturais e históricas particulares daquele território. 


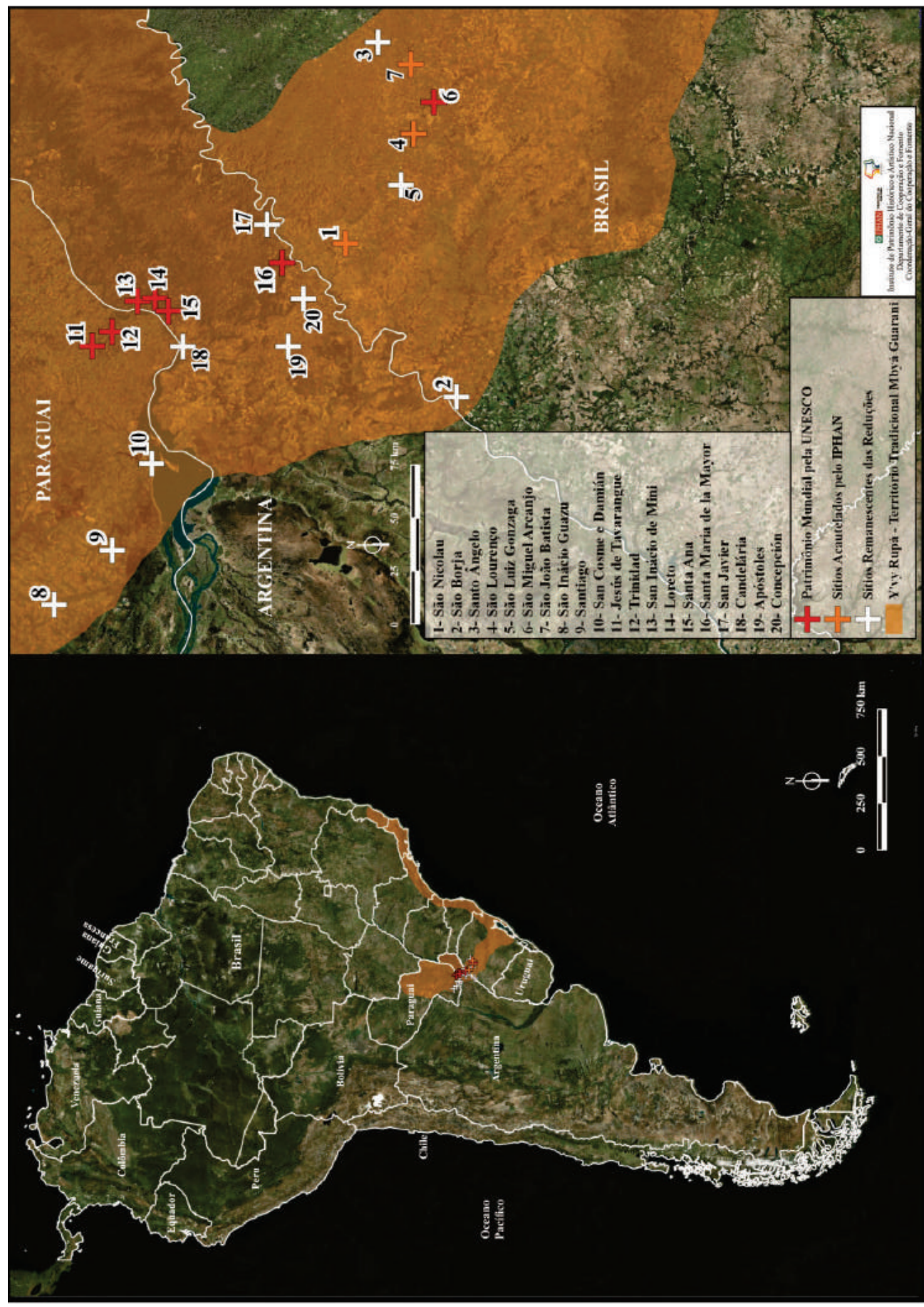

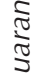

(ี) $\infty$

$\cdot \frac{0}{0}$

证

$\stackrel{\mathscr{e}}{=}=$

\&

în

궁 운

$\pm \sum$

$\approx 0$

$.00 \div$

产

응

\& 0

들

\&

ब 


\section{Conclusão}

No período colonial, os Mbyá Guarani fizeram parte da organização e formação do território reducional, mas, para além de meros ajudantes, a historicidade aponta para um protagonismo indígena nesse mesmo processo de construção. O trabalho servil indígena foi responsável tanto pela produção interna das reduções quanto pelo erguimento de edificações, como as igrejas. Seu trabalho ficou marcado na memória e nas paisagens. Porém, as narrativas de reconhecimento dos remanescentes das reduções como Patrimônio Cultural Brasileiro não davam a devida importância à participação Guarani na produção desse território.

Mas cabe dizer que o tombamento dos quatro sítios missioneiros pelo Instituto do Patrimônio Histórico e Artístico Nacional ocorreu em um período em que os discurso nacional era outro, as minorias costumeiramente eram negligenciadas. Ao longo do tempo esse cenário foi se alternando, dando espaço a novas narrativas, legitimando as experiências de outros grupos, para além da maioria branca. E, como reflexo dessa nova conjuntura, entre os anos de 2004 a 2008, o mesmo instituto realizou um Inventário Nacional de Referências Culturais em quatro aldeias Mbyá Guarani no Rio Grande do Sul, o que possibilitou a identificação e reconhecimento da Tava Guarani.

A Tava é um lugar sagrado para o povo Mbyá, de tal modo que ao identificar uma, eles necessitam construir uma casa de oração ao lado e erguer uma nova aldeia; ela se torna um dos elementos determinantes para a fixação deles naquele espaço. Assim, nota-se que a relação desse grupo com a Tava está intrinsecamente ligada à apropriação do território. Logo, a existência da Tava no município de São Miguel das Missões se torna um dos fundamentos da permanência desse grupo ali, e seu consequente reconhecimento como Patrimônio Imaterial Brasileiro ajuda a legitimar o direito deles de permanecerem no local.

O fato é que a territorialização Mbyá Guarani é assunto bastante complexo de ser debatido, uma vez que envolve o seu modo de vida unido às questões místico-cosmológicas de apropriação do espaço. O território Mbyá está além do plano físico e cartográfico, no entanto, é neste plano que ele é utilizado, através da ocupação, fixação e sobrevivência. O território tradicional Guarani, que segue desde o Paraguai até o Espírito Santo, só é tradicional porque compõe os espaços por eles ocupados ao longo dos anos, além de ser a rota por eles percorrida em busca de sua Terra sem Mal. As demarcações realizadas dentro desse território tradicional maior é uma maneira de assegurar seus direitos de acesso à terra, possibilitando os intercâmbios entre as aldeias, de modo a dar continuidade ao princípio da territorialidade livre, mesmo que de maneira mais restritiva.

Estudos a respeito da territorialidade e do território Mbyá Guarani tendem a expressar essa complexidade existente em meio a este assunto. Assim, se tornam fundamentais para ampliar esta rede de debates, proporcionar maior visibilidade e possibilitar a legitimação das lutas e direitos desse povo que, como tantos outros, sofreu no processo de construção da identidade nacional brasileira e, ainda sofre com a falta de acesso igualitário aos direitos sociais. Portanto, o presente trabalho buscou apresentar brevemente o que se compreende por território tradicional Guarani e sua relação com seus ocupantes, neste caso, os próprios Mbyá. Por outro lado, o trabalho também trouxe para o debate o reconhecimento da Tava de São Miguel Arcanjo como Patrimônio Imaterial Brasileiro e Patrimônio Cultural do MERCOSUL. Diante do que foi exposto, entende-se que tais reconhecimentos proporcio- 
nam uma maior visibilidade às referências culturais Guarani, ampliando o leque de manifestações culturais brasileiras e, inclusive, do MERCOSUL. Na verdade, as manifestações sempre existiram, apenas eram excluídas do rol cultural e agora vêm adquirindo espaço e respeito, sendo valorizadas e reconhecidas. É uma forma de romper com o paradigma civilizador branco europeu, e permitir conhecer o que há para além disso.

\section{Referências Bibliográficas}

BAPTISTA, J. O temporal: estrutura, dinâmica e funcionamento dos povoados reducionais. Dossiê Documental I (Consultoria Histórica). Museu das Missões/IPHAN, São Miguel das Missões, 2010.

HAESBAERT, R. O mito da desterritorialização: do fim dos territórios à multiterritorialidade. Rio de Janeiro: Bertrand Brasil, 6. ed., 2011.

INSTITUTO DO PATRIMÔNIO HISTÓRICO E ARTÍSTICO NACIONAL. Tava: lugar de referência para os Guarani. Dossiê de Registro - IPHAN, 2014.

LADEIRA, M. I. As demarcações Guarani, a caminho da terra sem mal. Acervo CTI, 1996

. Necessidade de novas políticas para o reconhecimento do território Guarani. 49 Congresso Internacional de Americanistas. Quito/Equador, 1997.

PONTES, B. M. S. As bases geopolíticas dos sete povos das missões. Revista de Geopolítica, Ponta Grossa, v. 1, n. 2, p. 57-71, 2010.

STELLO, V. F. Além das reduções: a paisagem cultural da região missioneira. Tese de Doutorado - Programa de Pós-graduação em Planejamento Urbano e Regional da Universidade Federal do Rio Grande do Sul. Porto Alegre, 2013.

TEAO, K. M. Território e identidade dos Guarani Mbya do Espírito Santo (1967-2006). Tese de Doutorado - Programa de Pós-Graduação em História da Universidade Federal Fluminense. Rio de Janeiro, 2015.

Recebido em: 17/12/2018

Aceito em: 25/03/2019

\footnotetext{
1 INSTITUTO DO PATRIMÔNIO HISTÓRICO E ARTÍSTICO NACIONAL, Dossiê de Candidatura Missões Jesuíticas Guarani, Moxos e Chiquitos apresentado à Comissão do Patrimônio Cultural, MERCOSUL Cultural. 2015.

2 Refere-se a uma plataforma colaborativa que organiza e disponibiliza dados georreferenciados sobre os territórios ocupados pelos povos Guarani na América do Sul. Surgiu a partir do desenvolvimento do Projeto Valorização do Mundo Cultural Guarani, realizado pelo IPHAN. Disponível em: https://guarani.map.as/\#!/. Acesso em: mar. 2019.
} 